\title{
High probability of pet dogs encountering the sylvatic cycle of Echinococcus multilocularis in a rural area in Hokkaido, Japan
}

\author{
Takao IRIE ${ }^{1) *}$, Kyoji YAMADA ${ }^{2)}$, Yasuyuki MORISHIMA ${ }^{3)}$ and Kinpei YAGI') \\ ${ }^{1)}$ Medical Zoology Group, Department of Infectious Diseases, Hokkaido Institute of Public Health, \\ North 19, West 12, Kita-ku, Sapporo, Hokkaido 060-0819, Japan \\ 2)Yamada Veterinary Clinic, Midorimachi-Kita 1-8-3, Nakashibetsu, Hokkaido 086-1165, Japan \\ ${ }^{3)}$ Department of Parasitology, National Institute of Infectious Diseases, Toyama 1-23-1, Shinjuku-ku, \\ Tokyo 162-8640, Japan
}

\section{J. Vet. Med. Sci. \\ 81(11): 1606-1608, 2019}

doi: 10.1292/jvms.19-0307

Received: 5 June 2019

Accepted: 10 September 2019 Advanced Epub:

20 September 2019
ABSTRACT. Surveillance of Echinococcus multilocularis in 98 pet dogs kept in a rural area of Hokkaido, Japan, from March 2018 to March 2019 suggested infection in seven dogs (7.1\%) by E. multilocularis-specific copro-DNA examination, and one of them excreted E. multilocularis eggs that were identified by sequence analyses. Among the infected dogs, three were not allowed to run free when outdoors. Based on detection of E. multilocularis eggs in fox feces collected from roadsides in the same area, dogs kept in rural areas may have a high probability of becoming infected after preying on infected voles along such roadsides, even in domesticated settings. Therefore, examination along with periodic deworming administration is considered necessary to prevent transmission from dogs to owners.

KEY WORDS: dog, Echinococcus multilocularis, epidemiology, Japan, zoonosis

Every year, several human cases of alveolar echinococcosis caused by Echinococcus multilocularis (Cyclophyllidea: Taeniidae) are reported in Hokkaido, Japan [12]. Human infection occurs through accidental ingestion of parasite eggs excreted in feces of carnivorous definitive hosts such as foxes and dogs. In Hokkaido, the tapeworm is maintained through a fox-vole sylvatic cycle with high endemicity (30-40\% infection rate in the red fox) [8]. In endemic regions, pet dogs may also be infected with $E$. multilocularis, and are a potential source of infection of humans $[1,3,9]$. Dogs become infected with the tapeworm only when they prey on a metacestode-infected vole. Canine infection is assumed to be mostly dependent on a dog's behavior towards voles (which is mainly based on individual habit and/or discipline by the owner) and habitat, especially the distance from infected wild voles, rather than the dog's biological background (e.g., breed, age, or gender).

Dogs infected with E. multilocularis are mostly asymptomatic [2] making it difficult to detect infection through normal health checkups alone. Therefore, the risk of transmission from infected dogs to humans through shedding of parasite eggs remains a significant concern. Necropsy examination of stray/sheltered dogs (conducted in Hokkaido by the government since 1966) demonstrated $1.0 \%$ prevalence of E. multilocularis, but this may be an underestimate as the number of dogs examined has decreased in recent years [8]. A mass coprological study of pet dogs in Hokkaido in 1997-2007 revealed that E. multilocularis eggs were excreted in $0.3 \%$ of city dogs and $0.7 \%$ of dogs from towns and villages [14]. Study of shelter dogs in Sapporo city, Hokkaido, in 2013-2017 indicated infection in 1.9\% of dogs by E. multilocularis-specific copro-DNA examination [7]. However, data for rural areas, where E. multilocularis is endemic among wild animals, is lacking. We therefore assessed pet dogs living in rural towns of eastern Hokkaido for E. multilocularis using copro-DNA and fecal egg examinations, along with interviews of owners regarding the dog's living conditions.

From March 2018 to March 2019, 98 dogs kept by 79 owners who brought their dogs to an animal clinic in eastern Hokkaido for care were included in this study. Stool sample collection and owner interviews were conducted by one of the co-authors (Yamada K., DVM). Dog came from at least six towns near Nakashibetsu, Shibetsu District, eastern Hokkaido, where land use is mainly pasture for dairy farming and the population density is $10.0-34.7$ persons $/ \mathrm{km}^{2}$. To increase the sensitivity of the tests, diagnostic deworming was conducted before fecal collection; dogs were administered the deworming agent praziquantel (5 mg/kg body weight) by the veterinarian and feces deposited the day after administration was collected for examination $[4,6]$. Feces were 
heated to $70^{\circ} \mathrm{C}$ for $12 \mathrm{hr}$ to inactivate Echinococcus eggs and then stored at $-30^{\circ} \mathrm{C}$ until examination. Based on the results of a survey conducted at the time of fecal collection, the following information related to pathways of infection was obtained from the dog owners: 1) land use around the home (town, suburb, or farming area); 2) placement of dog's bed (always indoors or always/ sometimes outdoors); and 3) history of running outdoors (always leashed when outdoors, accidently broke free, allowed to run free, or unknown).

Copro-DNA examination specific for E. multilocularis was performed on $3 \mathrm{~g}$ of feces, as previously described [6], followed by confirmation by sequencing analysis of the cytochrome $c$ oxidase subunit 1 (COI) gene [13]. Fecal egg examination was performed using $1 \mathrm{~g}$ of feces with a modified sucrose flotation method (specific gravity of 1.27) [5]. For species identification, eggs were collected from the supernatant of the centrifuge tube on a nylon mesh (pore size $20 \mu \mathrm{m}$ ), and the COI and nuclear U1 spliceosomal RNA (U1 snRNA) genes were analyzed as previously described [7].

Copro-DNA examination identified 7 of $98 \mathrm{dogs}(7.1 \%)$ as being positive and E. multilocularis was confirmed in all positive samples by sequencing analysis; these dogs were strongly suggested to be infected with E. multilocularis. Taeniid eggs (Fig. 1) were detected by the flotation method (6 eggs per gram of feces) in one dog, which was also copro-DNA positive, and the eggs were identified to be from E. multilocularis by sequencing of the COI and U1 snRNA genes. Owner survey results concerning exposure of dogs to infection risk are shown in Table 1. Dogs that tested positive for copro-DNA were from homes with each type of land use. The prevalence in surveyed dogs was higher than that reported recently in sheltered dogs in Sapporo city using the same coprological methods [7]. The odds ratio of canine infections in the present study to those in that study was 3.9 (95\% confidence interval 0.99-15.5), and the difference in infection risk was suspicious but not significant, consistent with a previous study by Nonaka et al. [14].

In the same area that was home to the surveyed dogs, fox feces was collected, following the methods of Morishima et al. [11], from areas that foxes are likely to use, such as the edges of agricultural fields and along paths or roads. Fecal collection was conducted twice, in July $2018(n=73)$ and October $2018(n=69)$. Fox feces were heat-treated as described above and subjected to copro-DNA and fecal egg examination. In the fox feces, 45 of 142 (31.7\%) samples were positive for copro-DNA and 23 (16.2\%) were positive for $E$. multilocularis eggs. The positive rate by copro-DNA examination in fox feces was compatible with the recent report of E. multilocularis prevalence in foxes in Hokkaido by necropsy [8]. Moreover, it was clearly shown that E. multilocularis eggs are included in fox feces deposited along roadsides in the study area, and that could serve as an infection source for the intermediate host wild voles (mainly Myodes rufocanus bedfordiae in Hokkaido), which inhabit pastures.

From questionnaires to owners of the dogs, 42 (42.9\%) of the dogs included in our study were suspected of having a greater chance to capture an infected wild vole because they were permitted to run free outdoors. Four dogs with suspected infections had been allowed to run free on walks. When allowed to run free, even for only a few hours, dogs may catch infected voles when out of sight of their owners [10]; therefore, permitting dogs to run free should be avoided in E. multilocularis-endemic areas. However, among the other three dogs that were E. multilocularis-specific copro-DNA positive, two had a bed that was always placed indoors and were kept on a leash when outdoors. Considering that $16.2 \%$ of fox feces collected along the roadside contained detectable tapeworm eggs, infection of voles could occur in such locations. Although the home range of the vole M. rufocanus bedfordiae varies by population density, season and vegetation, it has been estimated at approximately $30 \mathrm{~m} \mathrm{[15].} \mathrm{Therefore,} \mathrm{it} \mathrm{is} \mathrm{possible}$ for dogs to encounter infected voles at the side of roads where owners take their pet dogs for walks, and the owners of dogs that

Table 1. Land use, exercise habits of pet dogs, and numbers of dogs with coproDNA positive findings confirming Echinococcus multilocularis infection

\begin{tabular}{lcc}
\hline \multirow{2}{*}{ Category } & \multicolumn{2}{c}{ Number of dogs } \\
\cline { 2 - 3 } & Surveyed & Copro-DNA positive (\%) \\
\hline Land use of the home & 54 & $2(3.7)$ \\
Town & 11 & $1(9.1)$ \\
Suburb & 33 & $4(12.1)$ \\
Farming area & & \\
Placement of dog's bed & 66 & $2(3.0)$ \\
Always indoors & 32 & $5(15.6)$ \\
Always/sometimes outdoors & & \\
of running free outdoors & 20 & $3(15.0)$ \\
Always leashed when outdoors & 6 & 0 \\
Accidentally broke free & 42 & $4(9.5)$ \\
Allowed to run free & 30 & 0 \\
Unknown & &
\end{tabular}

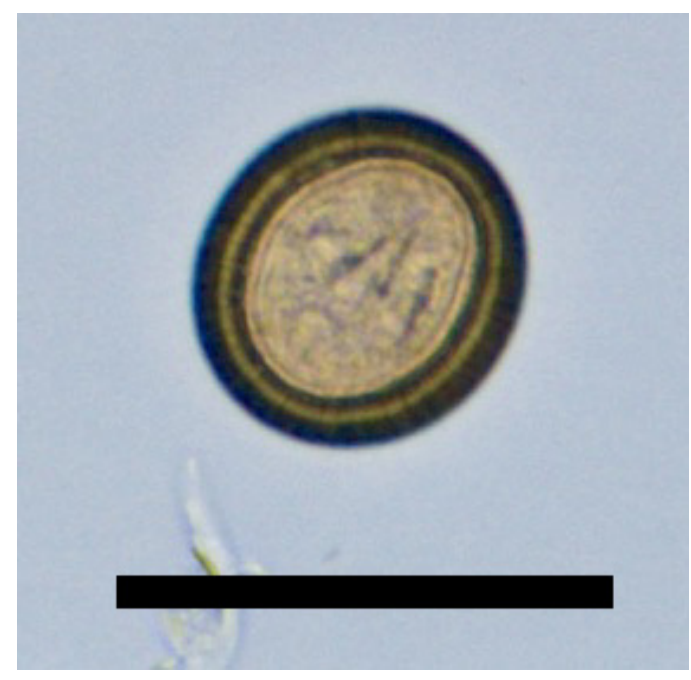

Fig. 1. Egg of Echinococcus multilocularis detected in feces of a pet dog. The oncosphere was observed in the embryophore. Scale bar $=50 \mu \mathrm{m}$. 
became infected despite being always leashed reported walking their dogs in areas with thick grass, such as along roadsides near their houses.

In fecal egg examination, eggs of Toxocara canis were detected in one dog, and those of Capillariidae in two other dogs. The latter eggs might be from voles infected with adult worm of Calodium hepaticum (syn. Capillaria hepatica) and passed thorough the intestines of dogs that preyed on vole. Detection of capillariid eggs in dog feces supports the suggestion that dogs can catch wild voles and thus are at risk of infection with E. multilocularis. In fact, seven dogs in our study had been seen by their owners to have interest in and/or to catch a wild vole, one of which dogs was copro-DNA positive, although the total number of dogs that had such habits could not be evaluated due to most owners unfortunately not responding to our questioner concerning this point.

In this study using evaluation of E. multilocularis infection by copro-DNA and fecal egg examinations, a high prevalence of $E$. multilocularis was found in pet dogs in a rural area in eastern Hokkaido, Japan. In rural areas where E. multilocularis is endemic, pet dogs could more easily encounter the sylvatic cycle of E. multilocularis than in urban areas; transmission of the tapeworm from fox to vole and from vole to dog may be expected to occur easily. Therefore, owners should avoid allowing their dogs to run free, and should carefully observe their dog's activity on walks, even if the dogs are leashed. Moreover, regular screening of pet dogs for the tapeworms is recommended, and periodic administration of deworming agents is considered an important measure to prevent transmission from dogs to owners.

AUTHOR DISCLOSURE STATEMENT. The authors have no relationships or support that might be perceived as constituting a conflict of interest.

ACKNOWLEDGMENT. This work was supported in part by Health and Labour Sciences Research Grant number H30-Shinkogyosei-Shitei-001.

\section{REFERENCES}

1. Budke, C. M., Campos-Ponce, M., Qian, W. and Torgerson, P. R. 2005. A canine purgation study and risk factor analysis for echinococcosis in a high endemic region of the Tibetan plateau. Vet. Parasitol. 127: 43-49. [Medline] [CrossRef]

2. Deplazes, P. and Eckert, J. 2001. Veterinary aspects of alveolar echinococcosis—a zoonosis of public health significance. Vet. Parasitol. 98: 65-87. [Medline] [CrossRef]

3. Gottstein, B., Saucy, F., Deplazes, P., Reichen, J., Demierre, G., Busato, A., Zuercher, C. and Pugin, P. 2001. Is high prevalence of Echinococcus multilocularis in wild and domestic animals associated with disease incidence in humans? Emerg. Infect. Dis. 7: 408-412. [Medline] [CrossRef]

4. Guo, Z., Li, W., Peng, M., Duo, H., Shen, X., Fu, Y., Irie, T., Gan, T., Kirino, Y., Nasu, T., Horii, Y. and Nonaka, N. 2014. Epidemiological study and control trial of taeniid cestode infection in farm dogs in Qinghai Province, China. J. Vet. Med. Sci. 76: 395-400. [Medline] [CrossRef]

5. Ito, S. 1980. Modified Wisconsin sugar centrifugal-flotation technique for nematode eggs in bovine feces. Nippon Juishikai Zasshi 33: $424-429$ (in Japanese with English Summary).

6. Irie, T., Ito, T., Kouguchi, H., Yamano, K., Uraguchi, K., Yagi, K. and Nonaka, N. 2017. Diagnosis of canine Echinococcus multilocularis infections by copro-DNA tests: comparison of DNA extraction techniques and evaluation of diagnostic deworming. Parasitol. Res. 116: 2139-2144. [Medline] [CrossRef]

7. Irie, T., Mukai, T. and Yagi, K. 2018. Echinococcus multilocularis surveillance using copro-DNA and egg examination of shelter dogs from an endemic area in Hokkaido, Japan. Vector Borne Zoonotic Dis. 18: 390-392. [Medline] [CrossRef]

8. Kamiya, M. 2007. Collaborative control initiatives targeting zoonotic agents of alveolar echinococcosis in the northern hemisphere. J. Vet. Sci. 8: 313-321. [Medline] [CrossRef]

9. Kamiya, M., Lagapa, J. T. G., Nonaka, N., Ganzorig, S., Oku, Y. and Kamiya, H. 2006. Current control strategies targeting sources of echinococcosis in Japan. Rev. - Off. Int. Epizoot. 25: 1055-1065. [Medline] [CrossRef]

10. Morishima, Y., Sugiyama, H., Arakawa, K. and Kawanaka, M. 2006. Echinococcus multilocularis in dogs, Japan. Emerg. Infect. Dis. 12: 12921294. [Medline] [CrossRef]

11. Morishima, Y., Tsukada, H., Nonaka, N., Oku, Y. and Kamiya, M. 1999. Coproantigen survey for Echinococcus multilocularis prevalence of red foxes in Hokkaido, Japan. Parasitol. Int. 48: 121-134. [Medline] [CrossRef]

12. National Institute of Infectious Diseases. 2019. Echinococcosis in Japan, 1999-2018. Infect. Agents Surveill. Rep. 40: 33-34.

13. Nonaka, N., Hirokawa, H., Inoue, T., Nakao, R., Ganzorig, S., Kobayashi, F., Inagaki, M., Egoshi, K., Kamiya, M. and Oku, Y. 2008. The first instance of a cat excreting Echinococcus multilocularis eggs in Japan. Parasitol. Int. 57: 519-520. [Medline] [CrossRef]

14. Nonaka, N., Kamiya, M., Kobayashi, F., Ganzorig, S., Ando, S., Yagi, K., Iwaki, T., Inoue, T. and Oku, Y. 2009. Echinococcus multilocularis infection in pet dogs in Japan. Vector Borne Zoonotic Dis. 9: 201-206. [Medline] [CrossRef]

15. Ota, K. and Higuchi, S. 1984. Activity. pp. 77-118. In: Study on Wild Murid Rodents in Hokkaido (Ota, K. ed.), Hokkaido University Press, Sapporo (in Japanese). 